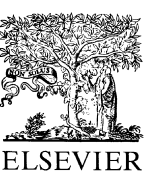

\title{
Requirements of Circulatory Support During Liver Transplantation: Are Patients With Familial Amyloidosis Different From Other Patients?
}

\author{
J.S. Viana, C. Bento, H. Vieira, S. Neves, C. Seco, R. Perdigoto, A.L. Craveiro, and L. Furtado
}

$\mathrm{F}^{\prime}$ MILIAL amyloidotic polyneuropathy (FAP) is a genetic dominant disease with a meaningful prevalence in Portugal, Sweden, and Japan. A large number of biochemistry anomalies could underlie this disease but by far the most frequent is the transthyretin methionine 30 anomaly (FAP ATTR Met 30$)^{1}$ whose symptoms start in adult age and death ensues commonly 10 to 15 years after the initial complaints. Liver transplantation is the only therapy that has proved to stop this disease. As opposed to transplant recipients with liver diseases, FAP patients present without preoperative coagulation disorders and portal hypertension, and the transplant tends to be technically easier, with less blood loss and shorter operating time. ${ }^{2,3}$ Nevertheless the circulatory involvement is always present in the natural course of this disease with autonomic dysfunction being a characteristic finding and cardiac arrhythmias and diastolic dysfunction being frequently observed. ${ }^{4} \mathrm{~A}$ high incidence of severe hypotension is reported during liver transplant in $\mathrm{FAP}^{2,5}$ and rhythm and intracardiac conduction anomalies have also been reported as a troublesome problem during FAP anesthesia. ${ }^{6}$ The aim of this study was to assess the intraoperative interventions on the circulatory system and to correlate them with the findings of preoperative routine examinations and intra-operative events.

\section{PATIENTS}

Group I included all 90 FAP ATTR Met 30 recipients of first liver transplant during a 7-year period, 50 male and 40 female, with age of $35.6 \pm 7.2$ years, weight of $56.4 \pm 11.9 \mathrm{~kg}$, body mass index (BMI) of $20.8 \pm 4.1 \mathrm{~kg} / \mathrm{m}^{2}$, disease duration (since the first symptom) of $4.8 \pm 2.5$ years, and a neurologic score of $33.9 \pm 12.6$ in the scale of Macedo and col. Group II included all the 125 adults (79 male, 46 female) with other diseases that received a first liver transplant during the same period. Groups were not different with regard to height and sex. Group II was older $(42.3 \pm 12.8$ years, $P<.001)$, and had a greater weight $(65.7 \pm 12.0 \mathrm{~kg}, P<.001)$ and BMI $\left(23.8 \pm 4.3 \mathrm{~kg} / \mathrm{m}^{2}, P<.001\right)$. Hematologic and liver function tests were normal in group I. Group II presented lower hemoglobin $(P<.001)$, fibrinogen $(P<.001)$, and albumin $(P<.001)$ and higher prothrombin time $(P<.001)$, direct $(P<.001)$ and total bilirubin $(P<.001)$, AST $(P<.001)$, ALT $(P<.001)$, and creatinine $(P<.001)$. The transplant was done by classic technique in 27 patients $(30.0 \%)$ of group I and $39(31.2 \%)$ of group II $(P=\mathrm{ns})$ and by piggy-back technique in the remaining. Seventeen patients $(18.9 \%)$ in group I and none in group II had a permanent pacemaker.

\begin{abstract}
METHOD
Anaesthesia, monitoring, and circulatory support protocols were identical in the two groups and did not change during the years of the study. Low-dose dopamine ( $3 \mu \mathrm{g} / \mathrm{kg} / \mathrm{min}$ or less) was used in all patients. Higher doses of dopamine were used as a first line circulatory support. Dobutamine was used to treat low cardiac output with adequate filling pressures and phenylephrine to treat vasodilatation. Antiarrhythmic agents or vasodilators were used as standard in general practice. Emergency transcutaneous pacing was always available. Group I values were compared with group II values by Mann-Whitney $U$ test or chi-square test followed by Fisher test, as appropriate. Within each group, if one drug was used in a number of patients that allowed subsequent statistics, patients that used it and patients that did not use it were compared with the same statistical tests. Data as mean \pm standard deviation.
\end{abstract}

\section{RESULTS}

Venovenous bypass was used in $31.1 \%$ of group I and $33.6 \%$ of group II $(P=$ ns). Group I patients needed $5.2 \pm$ 9.4 units of red blood cells (RBC), $12.7 \pm 16.6$ units of fresh frozen plasma (FFP), and $3.4 \pm 8.9$ units of platelets. Blood products consumption was significantly higher in group II: $13.1 \pm 12.7$ units of $\mathrm{RBC}(P<.001), 26.4 \pm 21.4$ units of FFP $(P<.001)$, and $9.0 \pm 8.6$ units of platelets $(P<.001)$. Except for low-dose dopamine, at least one sympathomimetic drug was used in $75.6 \%$ of group I and $38.4 \%$ of group II patients $(P<.001)$. Dopamine $(5 \mu \mathrm{g} / \mathrm{kg} / \mathrm{min}$ or more), dobutamine, phenylephrine, and epinephrine were respectively used in $43.3 \%, 2.2 \%, 48.9 \%$, and $7.8 \%$ of group I patients. The respective values in group II patients were 27.2\% $(P<.05), 12.8 \%(P=\mathrm{ns}), 3.2 \%(P<.001)$, and $4.0 \%(P=\mathrm{ns})$. Lidocaine was used in $7.8 \%$ of group I and $3.2 \%$ of group II patients $(P=\mathrm{ns})$. Norepinephrine, digoxin, verapamil, amiodarone, sodium nitroprusside, or nitroglycerine were used in a maximum of one patient in each group $(P=\mathrm{ns})$. Emergency pacing was never used.

Within group II, the patients that needed inotropic drugs had lower albumin $(P<.05)$ and higher creatinine

From the Department of Transplantation and Department of Anaesthesiology, University Hospitals of Coimbra, Coimbra, Portugal.

Address reprint requests to $\mathrm{Dr}$ Joaquim Viana, Department of Anaesthesiology, University Hospitals of Coimbra, 3049 Coimbra Codex, Portugal. E-mail:jvviana@huc.min-saude.pt. 
$(P<.05)$ in the preoperative period and consumed more RBC $(15.0 \pm 11.3$ vs $12.0 \pm 13.3$ units, $P<.05)$ and total number of blood products $(69.8 \pm 44.3$ vs $55.2 \pm 49.9$ units, $P<.05)$ than the remaining patients of the same group. Within group I, we are unable to find any difference between the patients that needed sympathomimetric drugs and the patients that did not require its use.

\section{DISCUSSION}

Our study showed that FAP patients needed more pharmacologic support of the circulation during liver transplantation than the patients with other diseases and these differences were particularly important concerning pure vasoconstrictor drugs. The high percentage of FAP recipients who needed phenylephrine and the low percentage that needed dobutamine certainly reflects a high incidence of sudden vasodilatation during their transplants, and also the rarity of low cardiac output as consequence of inappropriate contractility, according to previous reports. ${ }^{2,5}$

Regarding group II, some evidences suggested that the intraoperative use of sympathomimetic drugs was related to poor preoperative condition (lower albumin, higher creatinine) and higher blood loss during surgery. In contrast, similar relations were not observed in group I. We found the need for drugs as independent of blood loss, nutritional condition, or neurologic score, suggesting a particular role of the circulatory involvement itself. The high number of patients that needed vasoconstrictors, including patients in very early stages of the disease, and the finding that this need is not related to the duration of the disease suggested that conditions that predispose to hypotension appear early in the course of the disease.

Pacing deserves a particular discussion as it could be an option to use a transvenous pacemaker in all FAP liver transplants. ${ }^{6,7}$ In our series, more than $80 \%$ of patients did not have any kind of pacemaker during the transplantation and no need for emergency pacing was observed. We cannot exclude that severe bradyarrhythmias could be a risk during liver transplantation for FAP, but we can certainly exclude that they constitute a source of frequent complications when the patients with indication for permanent pacemaker had their pacemakers implanted before the surgery.

\section{REFERENCES}

1. Saraiva MJM, Birken S, Costa PP, et al: J Clin Invest 74:104, 1984

2. Eleborg L, Suhr O, Gunnarsson L: Amyloid Int J Exp Clin Invest 4:24, 1997

3. Viana JS, Bento C, Vieira H, et al: Rev Port Cardiol 18:689, 1999

4. Fonseca C, Ceia F, Carvalho A, et al: Rev Port Cardiol 6:101, 1997

5. Viana JS, Furtado AL: Br J Anaesth 82(suppl 1):41, 1999

6. Eriksson P, Boman K, Jacobsson B, et al: Acta Anaesthesiol Scand 30:317, 1986

7. Eleborg L, Suhr O, Ericzon BG, et al: Neuromusc Disord 6(suppl):S71, 1996 